Thermal Simulation of Shale Gas Recovery involving the use of microwave Heating.

John Fianu ${ }^{\mathrm{a}}$, Jebraeel Gholinezhad ${ }^{\mathrm{a}}$ and Mohamad Hassan ${ }^{\mathrm{a}}$

${ }^{a}$ School of Energy and Electronics Engineering, University of Portsmouth, PO1 3DJ, Portsmouth, UK *Jebraeel.gholinezhad@port.ac.uk 


\title{
Thermal Simulation of Shale Gas Recovery involving the use of microwave Heating.
}

\author{
Recent technological advancement in drilling for shale gas such as hydraulic fracturing, \\ has meant that more gas can be recovered from the ultra-tight matrix of the shale \\ formation. However, significant quantities of adsorbed gas are still left unproduced \\ even with this breakthrough in accessing gas previously unattainable due to the low \\ permeability of shale. In this paper, a coupled electromagnetic -thermal model has \\ been developed to investigate the production of adsorbed gas from shale gas \\ reservoirs using microwave heating. A dual porosity -dual permeability model is \\ developed for the system of shale gas with account of both viscous and Knudsen \\ diffusion in the matrix. Results from simulation indicated that microwave heating can \\ improve cumulative production by $25 \%$ in a period of one year by accelerating \\ desorption of the adsorbed gas. Further results also indicated higher penetration \\ depth for microwave frequency of $915 \mathrm{MHz}$. This study provides useful insights into \\ microwave assisted shale gas recovery.
}

Keywords: Shale gas, Adsorption, Temperature-dependent Adsorption model, Thermal Stimulation, Microwave Heating

\section{Introduction}

Thermal stimulation strategies have been used by several researchers as a way of improving oil recovery by increasing formation temperature. It has grown in prominence especially in unconventional reservoirs such as heavy oil and shale oil. Recent application of thermal stimulation can also be found in coal bed methane reservoirs. The different kinds of thermal stimulation that is currently being used in unconventional reservoirs include cyclic steam injection, in-situ combustion and Steam assisted gravity drainage (SAGD). The use of electric heating is particularly useful where steam cannot be used because of the formation depth, excessive heat losses and cases where there exist thief zones (Sierra et al., 2001). Thermal stimulation can account for about $60 \%$ of oil production in our world today (Chekhonin et al., 2012).Though several studies have been conducted on how to improve heavy oil/shale oil recovery by elevating the formation temperature, very few have considered the implementation of similar thermal techniques as a way of enhancing gas recoveries (Yue et al., 2015). 
Wang (2016) demonstrated the efficiency of thermal stimulation largely depended on the gas adsorption and rock properties of the formation. Thus by altering the gas adsorption/desorption behaviour through thermal stimulation, more gas could be recovered from hydraulically fractured shale gas reservoirs. Wang et al. (2015) also used similar techniques in coal bed methane reservoirs by investigating the application of thermal stimulation of hydraulic fractured coalbed methane reservoir. Altering the gas adsorption and desorption behaviour through thermal stimulation in coal bed methane (CBM) has also resulted in increased gas recoveries. Studies conducted by Salmachi and Haghighi (2012) showed that as the formation temperature increased through a process of hot water injection for a period of 2 years, the gas adsorption/ desorption process was altered. This led to increase in methane production by $58 \%$ during 12 years production. They argued that thermal treatment in CBM results in the breakdown of bonds between the gas molecules and surfaces which ultimately alters the adsorption/desorption properties of the coal. In shale gas, adsorption results in an exothermic reaction. Thereby, shale gas adsorption capacity is expected to decrease with increasing temperature. The temperature dependence of adsorption capacity is greatly controlled by the isosteric heat, which also depends on the surface coverage. Many experimental studies have been conducted on the influence of temperature on adsorbed shale gas content (Charoensuppanimit et al., 2015; Chen et al., 2011; Clarkson, 2003; Gasparik et al., 2015; Guo, 2013; Hu, 2014; Ji et al., 2014; Lu et al., 1995; Rexer et al., 2013; Ye et al., 2016).

In- situ combustion has also been studied by Chapiro and Bruining (2015) as a means of improving the effective permeability's of shale gas reservoirs. Shale formations are porous rocks with low permeability (Santos et al. 2019). Thus the permeability of shale rocks is a key factor towards improving the production from tight/shale gas reservoirs. By increasing the effective permeability, the natural gas would be able to flow easily to the surface and hence recoveries would improve. The authors argued that , the combination of hydraulic fracturing and horizontal drilling has allowed more gas to be easily extracted from shale, however its impact on the environment suggests that alternative techniques needs to be explored. Similar studies also suggests thermal stimulation of shale gas reservoirs can result in effective permeability improvement just like in oil shales (Busch and Amann-Hildenbrand, 2013; Sanmiguel et al., 2002). According to Jamaluddin et al.(2000) thermal treatments in tight gas reservoirs enhances the permeability of the formation by vaporizing the capillary blocked water, dehydrating the clay bound water and creating thermally induced micro-fractures. Their studies demonstrated increase in permeability as much as over $50 \%$ for core samples that were exposed to heat treatments. 
In recent years, there have been developments in the use of coupled electromagnetic thermal modelling to quantify and visualize microwave heating, however these developments have been focused primarily on food, wood and mineral with little applications in shale and coal (Li et al., 2017; Liu et al., 2018).

There are basically three main kinds of electrical heating that is mostly used in the oil and gas industry as a stimulating strategy for improved production. These include low frequency electric heating, inductive heating where an alternating current is used and finally high frequency heating in the form of microwave (Sahni et al., 2000). Microwave are also known as electromagnetic waves that have frequency range between $300 \mathrm{MHz}$ and $300 \mathrm{GHz}$ with wavelength of $1 \mathrm{~mm}$ to $1 \mathrm{~m}$ (Denny, 2007). The application of microwave technology are varied ranging from application in food processing, pharmaceutical industry, wood processing to ceramics. In the petroleum industry, it is often seen as an enhanced recovery method targeting mostly unconventional resources such as heavy oil and tar sands. Microwave application is preferred where the medium is made up of polar molecules rather than non-polar molecules which cannot absorb the microwave energy. Water content in the formation plays a key role in microwave heating since the high frequency wave's act on the water molecules causing them to heat up (through dipole rotation or Molecular rotation causing friction as a result of the rotation ) and the heat is transmitted towards the surrounding formation.

Microwave heating is sometimes referred to as dielectric heating. Dielectric heating refers mainly to heating by electric field due to the presence of dipoles in polar molecules. The heating process is also mainly influenced by the dielectric properties of the medium. Other factors that controls the temperature distribution within the medium are the heat capacity and thermal conductivity of the material.

Conventional heating methods such as conduction, convention and radiation are the main heating sources for both the internal and external medium but usually at a much slower heating speeds compared with heating by microwave. Instead of heat transfer like most conventional heating, the energy is converted from electromagnetic energy to thermal energy (Sun et al., 2016).

The use of microwave heating in oil and gas reservoirs is mostly limited to heavy oil production with limited application or studies to gas production in shale gas reservoirs (Mutyala et al., 2010). According to Mutyala et al. (2010), commercial application of microwave heating is lacking due to high initial setup cost and the uncertainty surrounding its potential. However, they went further to argue that if it could be demonstrated that the potential of microwave heating 
increases production and ultimately profits on a large scale , then microwave heating could be useful application in the future for the petroleum industry.

Several advantages can be obtained from the use of microwave heating over conventional electric heating as well as other thermal stimulation methods. Some of the challenges of thermal stimulation using fluid injection like steam can be easily overcome by the use of microwave heating. These include low initial fluid injection, steam override and difficulty in establishing communication paths between wells. Hiebert et al.(1986) argues that these problems hardly occur in microwave heating. For instance, they argue that since no fluid is involved in microwave heating, the problem of low initial fluid injection can be easily avoided, also the penetration depth of microwaves normally occurs around the near wellbore and deeper into the formation allowing for large portion of the reservoir to be stimulated. Finally, production can easily be obtained during or immediately after the microwave is injected provided sufficient formation pressure is available. In order to study shale gas interactions during microwave heating, a fully coupled electromagnetic-thermal model has been developed. The development of such a coupled electromagnetic-thermal model enables the understanding of microwave heating with shale gas considering non-Darcy effects. The effect of microwave frequency on temperature evolution and also on production have been investigated. Free gas evolution during microwave heating and also overall production with and without microwave heating has been investigated. Results from the simulation exercise will provide further knowledge in the use and application of microwave heating in shale gas recovery especially targeting the adsorbed gas stored in the shale matrix.

\section{Material and Methods}

\subsection{Gas flow equation}

Mass balance equation can be obtained for both matrix and fracture system using continuum approach of dual porosity dual permeability.

$$
\begin{aligned}
& \left(\frac{d M}{d t}\right)_{m}+(\nabla \cdot(\rho u))_{m}=(Q)_{m} \\
& \left(\frac{d M}{d t}\right)_{f}+(\nabla \cdot(\rho u))_{f}=(Q)_{f}
\end{aligned}
$$


Where subscript $m$ and $f$ refers to the matrix and fracture respectively.

The mass accumulation for matrix can be represented as

$$
M=\sum\left(\phi \rho_{g}+(1-\phi) q_{a d s}\right)
$$

With the corresponding partial differential form given as

$$
\frac{d M}{d t}=\frac{\partial\left(\rho_{g} \phi\right)}{\partial t}+\frac{\partial\left[(1-\phi) q_{a d s}\right]}{\partial t}
$$

Where $q_{a d s}$ is gas adsorption volume per unit bulk volume, this can be represented by the use of temperature dependent Langmuir model.

$q_{a d s}=\frac{\rho_{s} M w_{g}}{V_{s t d}}\left(\frac{\mathrm{V}_{L}\left(b_{o} \exp (-\Delta H / R T) p\right.}{1+\left(b_{o} \exp (-\Delta H / R T) p\right.}\right)$

Using the equation of state (EOS), the density of the gas can be expressed as

$$
\rho_{g}=\frac{m}{V}=\frac{p M}{Z R T}=\frac{\gamma}{Z} p
$$

For an ideal gas,

$$
\rho_{g}=\gamma p
$$

Due to the presence of only free gas within the fracture system, the mass accumulation can be expressed as

$$
\left(\frac{d M}{d t}\right)_{f}=\frac{\partial\left(\rho_{g} \phi\right)}{\partial t}=\left[\gamma \phi_{f}\right] \frac{\partial p_{f}}{\partial t}
$$

Due to the extremely low permeability in shale gas reservoir, conventional Darcy law cannot be used to represent the flow process in the matrix. Thus, gas transport in nanopores includes mechanisms such as Knudsen diffusion, viscous flow and slip flow. Knudsen diffusion is more likely to occur when the pore diameter is small enough so that the mean free path of the gas is close to the pore diameter. The flow vector term of both matrix and fracture considering both viscous flow and 
Knudsen diffusion results in

$$
\begin{aligned}
& \nabla \cdot(\rho u)_{m}=-\nabla \cdot\left(\rho_{g}\left(\frac{k_{m}}{\mu} \nabla p_{m}\right)\right)=-\nabla \cdot\left(\gamma p_{m}\left(\frac{k_{m}}{\mu} \nabla p_{m}\right)\right) \\
& \nabla \cdot(\rho u)_{f}=-\nabla \cdot\left(\rho_{f}\left(\frac{k_{f}}{\mu} \nabla p_{f}\right)\right)=-\nabla \cdot\left(\gamma p_{f}\left(\frac{k_{f}}{\mu} \nabla p_{f}\right)\right)
\end{aligned}
$$

Combining all of the above equation results in characterisation of gas flow in shale gas reservoir as

$$
\left[\gamma \phi_{m}+\frac{\left(1-\phi_{m}\right) M w_{g} P_{L} V_{L} \rho_{s}}{V_{s t d}\left(P_{L}+p_{m}\right)^{2}}\right] \frac{\partial p_{m}}{\partial t}-\nabla \cdot\left(\gamma p_{m}\left(\frac{k_{m}}{\mu} \nabla p_{m}\right)\right)=-T_{g}
$$

Where $P_{L}=1 / b$ and $b=b_{0} \exp (-\Delta H / R T)$

$$
\left[\gamma \phi_{f}\right] \frac{\partial p_{f}}{\partial t}-\nabla \cdot\left(\gamma p_{f}\left(\frac{k_{f}}{\mu} \nabla p_{f}\right)\right)=T_{g}-q_{p}
$$

Where the transfer of gas between the matrix and the fracture is therefore represented as

$$
T_{g}=\frac{k_{m} \rho_{g} \sigma\left(p_{m}-p_{f}\right)}{\mu}
$$

And

$$
\sigma=4\left(\frac{1}{L_{x}^{2}}+\frac{1}{L_{y}^{2}}+\frac{1}{L_{z}^{2}}\right)
$$

\subsection{Energy conservation Equation}

The two energy equations for the gas phase and the matrix can be written explicitly as

For matrix:

$$
(1-\phi) \rho_{m} c_{p, m} \frac{\partial T_{m}}{\partial t}=(1-\phi) \nabla \cdot\left(k_{T, m} \nabla T_{m}\right)+(1-\phi) q_{m}^{\prime \prime}+a h\left(T_{m}-T_{g}\right)
$$


For the gas:

$(\phi) \rho_{g} c_{p, g} \frac{\partial T_{m}}{\partial t}+(\phi) \nabla \cdot\left(-k_{T, g} \nabla T_{g}\right)+\rho_{g} c_{p, g} \nabla T \cdot q_{g}=\phi q_{g}^{\prime \prime}+a h\left(T_{m}-T_{g}\right)$

Where

$q_{g}$ is the velocity vector of the gas phase and $q^{\prime \prime}$ is the heat source term.

By assuming a local thermal equilibrium, the energy equation can easily be simplified the walls of the pores by setting the relation $T_{m}=T_{g}=T$ and by summing equation 15 and 16 together, we get the following expression

$\left(\rho c_{p}\right) \frac{\partial T}{\partial t}+\nabla \cdot\left(-K_{T} \nabla T\right)+\rho_{g} c_{p, g} q_{g} \cdot \nabla T=Q$

Where

$$
\begin{aligned}
& \left(\rho c_{p}\right)=(1-\phi) \rho_{m} c_{p, m}+\phi \rho_{g} c_{p, g} \\
& K_{T}=(1-\phi) k_{T, m}+\phi k_{T, g} \\
& Q=(1-\phi) q_{m}^{\prime \prime}+\phi q_{g}^{\prime \prime}
\end{aligned}
$$

Equation 18 is similar to the volumetric heat capacity at constant pressure, equation 19 is equivalent to thermal conductivity and equation 20 , is the overall heat source.

Microwave heating can be solved by coupling the heat and mass transfer equation with a source term. Rather than solving the Maxwell's equation for the electromagnetic field, lamberts law expressing power as an exponential decay could also be used to describe the source term (Campañone and Zaritzky, 2005; Zhou et al., 1995) by the expression

$$
P=P_{o} e^{(-2 \alpha d)}
$$

Where $P_{o}$ is the surface power, $d$ is the maximum distance measured from the surface and $\alpha$ is the attenuation factor, which is a function of the dielectric constant of the material. Where Maxwell's equation is used, the source term is determined by the EM power that is dissipated in the material due to its dielectric losses. This can be expressed by (Torres and Jecko, 1997; Zhao et al., 2011) 
$Q=\frac{1}{2}\left(\vec{E} \cdot \frac{\partial \vec{D}}{\partial t}-\vec{D} \cdot \frac{\partial \vec{E}}{\partial t}\right)$

And for the case of steady state time harmonic EM fields, this may yield

$Q=\frac{1}{2} \omega \varepsilon_{o} \varepsilon^{\prime \prime} E^{2}$

$Q$ is the absorbed power per unit volume $\left(\mathrm{W} / \mathrm{m}^{3}\right)$

Where $\omega$ is the angular frequency, $\mathcal{E}_{O}$ is the vacuum permittivity, $\mathcal{E}^{\prime \prime}$ refers to the imaginary part of the materials permittivity, $E$ is the amplitude of $\vec{E}$. The microwave power absorbed can also be represented as a function of the electric field (Chaiyo and Rattanadecho, 2013; Klayborworn et al., 2013)

$Q=2 \pi f \varepsilon_{o} \varepsilon_{r}^{\prime}(\tan \delta) E^{2}$

Where $\mathcal{E}_{r}$ represents relative dielectric constant, $\varepsilon_{o}$ is the permittivity of free space and $\tan \delta$ is the tangential loss coefficient.

Farag et al. (2012) describes the equation given by lamberts law as representing the local value of the power at a certain distance from the surface of the heated material while equation 21 represents generated power.

According to Wang (2016), the heat capacity of most formation is at least 100 times larger than that of gas phase and since formation porosity of a shale formation is normally less than $3 \%$, equation 16 18 are dominated by the terms of $(1-\phi) \rho_{m} c_{p, m},(1-\phi) k_{T, m}$ and $(1-\phi) q_{m}^{\prime \prime}$ respectively. Also, since the flow rate of the gas is limited by the low permeability of shale formation, and considering that the gas has low density, the term $\rho_{g} c_{p, g} q_{g} . \nabla T$ can be neglected in equation 15.

Therefore, we can simplify equation 15 as the following

$$
\left(\rho_{m} c_{p, m}\right) \frac{\partial T}{\partial t}+\nabla \cdot\left(-k_{T, m} \nabla T\right)=Q
$$


Equation 11, 13 and 25 can therefore be combined overall and with appropriate initial and boundary conditions, a complete description of the system coupled with heat can be achieved.

\subsection{Temperature -dependent Variables}

Temperature dependent variables are needed in order to investigate the process of thermal stimulation applications in shale gas reservoirs. Thus, several temperature dependent variables would have to be defined to enable the coupling of the previous governing equations for both the matrix and fracture system with the heat equation. The key variables to be explored include the gas adsorption capacity, gas density and the viscosity of the gas both of which are temperature dependent.

The most widely used adsorption model is the Langmuir isotherm. This model is able to describe the relationship between pressure and the adsorbed gas content as a function of pressure. The key disadvantage of this model is that it does not account for the effect of temperature on the adsorption of gas onto the shale matrix. To account for the effect of temperature, a temperature dependent Langmuir model has been adopted and used in the coupling process.

The modified Langmuir model can be expressed as follows (Fianu et al., (2018):

$q_{a d s}=\frac{\rho_{s} M_{g}}{V_{s t d}}\left(V_{L} \frac{b p}{1+b p}\right)$

Where $b=b_{0} \exp (-\Delta H / R T)$

Well established correlations have been used to derive gas viscosity. One of the most popular and comprehensive studies on the viscosities of natural gases was carried out by (Lee et al., 1966).

$u_{g}=K \exp \left(X \rho^{Y}\right)$

Where

$$
K=\frac{(7.77+0.0063 M) T^{1.5}}{122.4+12.9 M+T}, X=2.57+\frac{1914.5}{T}+0.0095 M, Y=1.11+0.04 X
$$

The fluid density is a function of temperature, pressure and composition when considered for a real gas system. Thus for flow in a porous media, the real gas law can be expressed as 
$\rho_{g}=\frac{M_{g} p}{Z R T}$

There are several equation of states or correlations that can be solved to obtain the Z-factor. In this study Hall and Yarborough correlation have been used to obtain the Z-factor.

$t=\frac{1}{T_{p r}}$

$A=0.06125 t e^{-1.2(1-t)^{2}}, B=14.76 t-9.76 t^{2}+4.58 t^{2}, C=90.7 t-242.2 t^{2}+42.4 t^{2}$,

$D=2.18+2.82 t$

$-A P_{p r}+\frac{y+y^{2}+y^{3}-y^{4}}{(1-\mathrm{y})^{3}}-B y^{2}+C y^{D}=0$

$T_{p r}=\frac{T}{T_{p c}}, P_{p r}=\frac{P}{P_{p c}}, z=\frac{A P_{p r}}{y}$

\subsection{Electromagnetic wave excitation}

The heating process using microwave can be modelled either analytically or numerically. Analytical solutions to microwave heat transfer has been performed by (Hossan and Dutta, 2011; Pincombe and Smyth, 1991). However due, to the complexities associated with the Maxwell's equation, almost all of the microwave heating process is solved using numerical techniques. Several researchers have modelled the process of microwave heating using numerical techniques such as the finite difference time domain method (FDTD) that was proposed by (Yee, 1966).

By assuming no charges or current, the Maxwell equations for linear and isotropic material can be written as:

$\nabla \times \vec{E}=-\frac{\partial \vec{B}}{\partial t}$

$\nabla \times \vec{H}=\frac{\partial \vec{D}}{\partial t}$

$\nabla \cdot \vec{D}=0$ 
$\nabla \cdot \vec{B}=0$

Where $\vec{D}(t)=\varepsilon \vec{E}, \vec{B}(t)=\mu \vec{H}$

To solve equation 28-31, Yee (1966) proposed a method called Finite Difference Time Domain (FDTD) as a three dimensional solution to Maxwell's equations. By substituting the constitutive relations into the Maxwell's equations we can obtain the following final set of equations

$$
\begin{aligned}
& \nabla \times \vec{E}=-\mu \frac{\partial \vec{H}}{\partial t} \\
& \nabla \times \vec{H}=\varepsilon \frac{\partial \vec{E}}{\partial t} \\
& \nabla \cdot(\mu \vec{H})=0 \\
& \nabla .(\varepsilon \vec{H})=0
\end{aligned}
$$

The relative permittivity is made up of two parts, real and imaginary parts. The real part refers to the dielectric constant $\varepsilon$ whereas the imaginary part refers to dielectric loss factor $\varepsilon "$. $\varepsilon_{r}=\varepsilon_{r}^{\prime}-j \varepsilon_{r}^{\prime \prime}$

Where the dielectric properties of a porous material is a function of temperature, this can be further defined as (Klayborworn et al., 2013)

$$
\begin{aligned}
& \varepsilon_{r}^{\prime}(T)=\phi \varepsilon_{r f l}^{\prime \prime}(T)+(1-\phi) \varepsilon_{r p a}^{\prime} \\
& \varepsilon_{r}^{\prime \prime}(T)=\phi \varepsilon_{r f l}^{\prime \prime}(T)+(1-\phi) \varepsilon_{r p a}^{\prime \prime}
\end{aligned}
$$

The loss tangent coefficient can be written as

$$
\tan \delta=\frac{\varepsilon_{r}^{\prime \prime}(T)}{\varepsilon_{r}^{\prime}(T)}
$$




\subsection{Courant stability criterion}

For numerical stability, the appropriate time step needs to be chosen according to stability conditions. In general, the courant condition is given as

$$
\Delta t \leq \frac{\Delta x}{c_{o} \sqrt{d}}
$$

$\Delta x$ is the grid size, with $d=1,2$ or 3 for one, two and three dimension problems respectively. The time step $\Delta t$ is however normally chosen as

$$
\Delta t=\frac{\Delta x}{2 c_{o}}(\text { Sullivan, 2000) }
$$

Finite difference time domain method have been widely used in solving most electromagnetic problems due to its simplicity. It was first proposed by Yee (1966) but have been improved over the years by other researchers. It has been successful applied in variety of problems such as antennas, electromagnetic absorption in the human body exposed to radiation and microchip circuits (Akram and Jasmy, 2012; Rathi et al., 2012; Toroğlu and Sevgi, 2014). Since the exact solution of Maxwell's equations is impossible, numerical methods such as FDTD can be applied. For the time dependent Maxwell's equations, discretization is achieved using central difference approximations to space and time with resulting finite difference equations solved using a leapfrog approach. The curl equations are written in FDTD form on a Yee cell as shown in figure 1. The electric and magnetic field are staggered in time so that the electric field will exist at integer time steps of $0, \Delta t, 2 \Delta t, \ldots$ and the magnetic field at half time steps of $\Delta t / 2, \mathrm{t}+\Delta t / 2,2 \mathrm{t}+\Delta t / 2, \ldots$ 


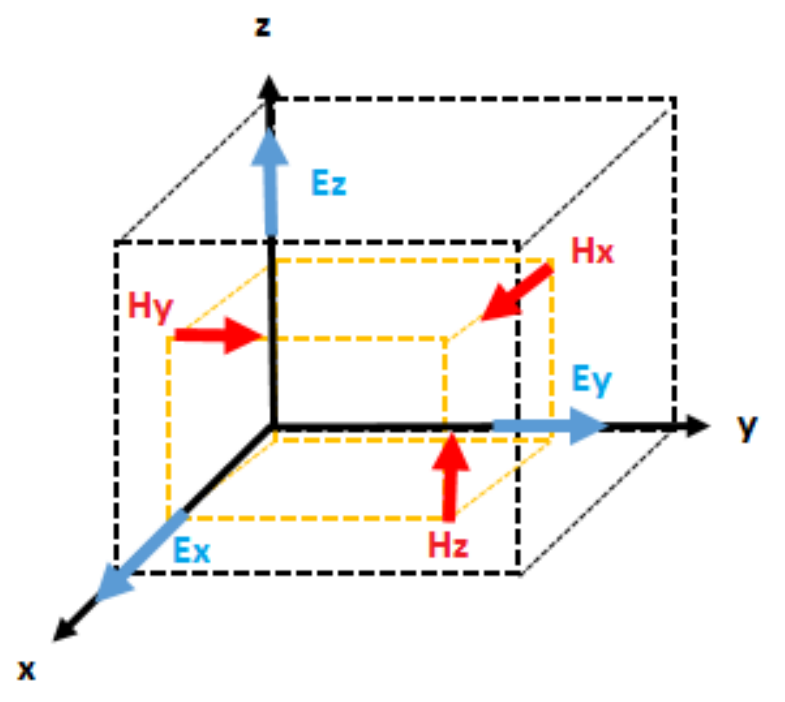

Figure $1:$ The Yee cell

In the main loop of the FDTD equation, an update equation are derived and the resulting equations are solved using the finite difference equations for the future time values of each fields.

$$
\begin{aligned}
& \left.H_{z}\right|_{t+\Delta t / 2} ^{i, j}=\left.H_{z}\right|_{t-\Delta t / 2} ^{i, j}+\left.\left(-\frac{c_{o} \Delta t}{\left.\mu_{z z}\right|^{i, j}}\right) C_{z}^{E}\right|_{t} ^{i, j} \\
& \left.\tilde{D}_{x}\right|_{t+\Delta t} ^{i, j}=\left.\tilde{D}_{z}\right|_{t} ^{i, j}+\left.\left(c_{o} \Delta t\right) C_{x}^{H}\right|_{t+\Delta t / 2} ^{i, j} \\
& \left.\tilde{D}_{y}\right|_{t+\Delta t} ^{i, j}=\left.\tilde{D}_{z}\right|_{t} ^{i, j}+\left.\left(-c_{o} \Delta t\right) C_{y}^{H}\right|_{t+\Delta t / 2} ^{i, j} \\
& \left.\tilde{E}_{x}\right|_{t+\Delta t} ^{i, j}=\left.\left(\frac{1}{\left.\varepsilon_{x x}\right|^{i, j}}\right) \tilde{D}_{x}\right|_{t+\Delta t} ^{i, j} \\
& \left.\tilde{E}_{y}\right|_{t+\Delta t} ^{i, j}=\left.\left(\left.\frac{1}{\varepsilon_{y y}}\right|^{i, j}\right) \tilde{D}_{y}\right|_{t+\Delta t} ^{i, j}
\end{aligned}
$$

\subsection{Numerical model of a 2D Reservoir}

In order to investigate the application of microwave technology in shale gas reservoirs, a 2D reservoir model is simplified with a waveguide in transverse electric (TE) mode. There are three categories of electromagnetic waves according to the longitudinal components of the electric field ( $\left.E_{z}\right)$ and the magnetic field $\left(H_{z}\right)$. With waves being transmitted along the z-axis for rectangular waveguide systems. These three categories are known as the transverse electromagnetic (TEM), 
transverse electric (TE) and transverse magnetic (TM). Where the $E_{z}=0$ and $H_{z}=0$, both $E$ and $H$ are said to be transverse to the direction of propagation. When this happens, the electromagnetic wave is normally referred to as TEM wave. In the transverse magnetic mode, the magnetic field is transverse to the direction of propagation while the electric field is parallel to the direction of propagation. For a TM wave, $E_{z} \neq 0$ and $H_{z}=0$. In transverse electric mode, $E_{z}=0$ while $H_{z} \neq 0$ with the electric field been transverse to the direction of propagation whilst the magnetic field remains parallel to the direction of propagation. The TE mode have been chosen as the mode of propagation for this work.

A microwave waveguide is located at the centre of the model. The microwave frequency is set at $2.45 \mathrm{GHz}$. The initial temperature of the reservoir is at $579.6^{\circ} \mathrm{R}$. The reservoir is divided into $21 \times 21$ matrix block with dimensions of $50 \mathrm{ft}$. x $50 \mathrm{ft}$. A summary of all computational parameters are taken from literature, experimental data or from our estimations and are given in Table 1. A schematic of a typical microwave heating in shale gas is shown in figure 2 below.

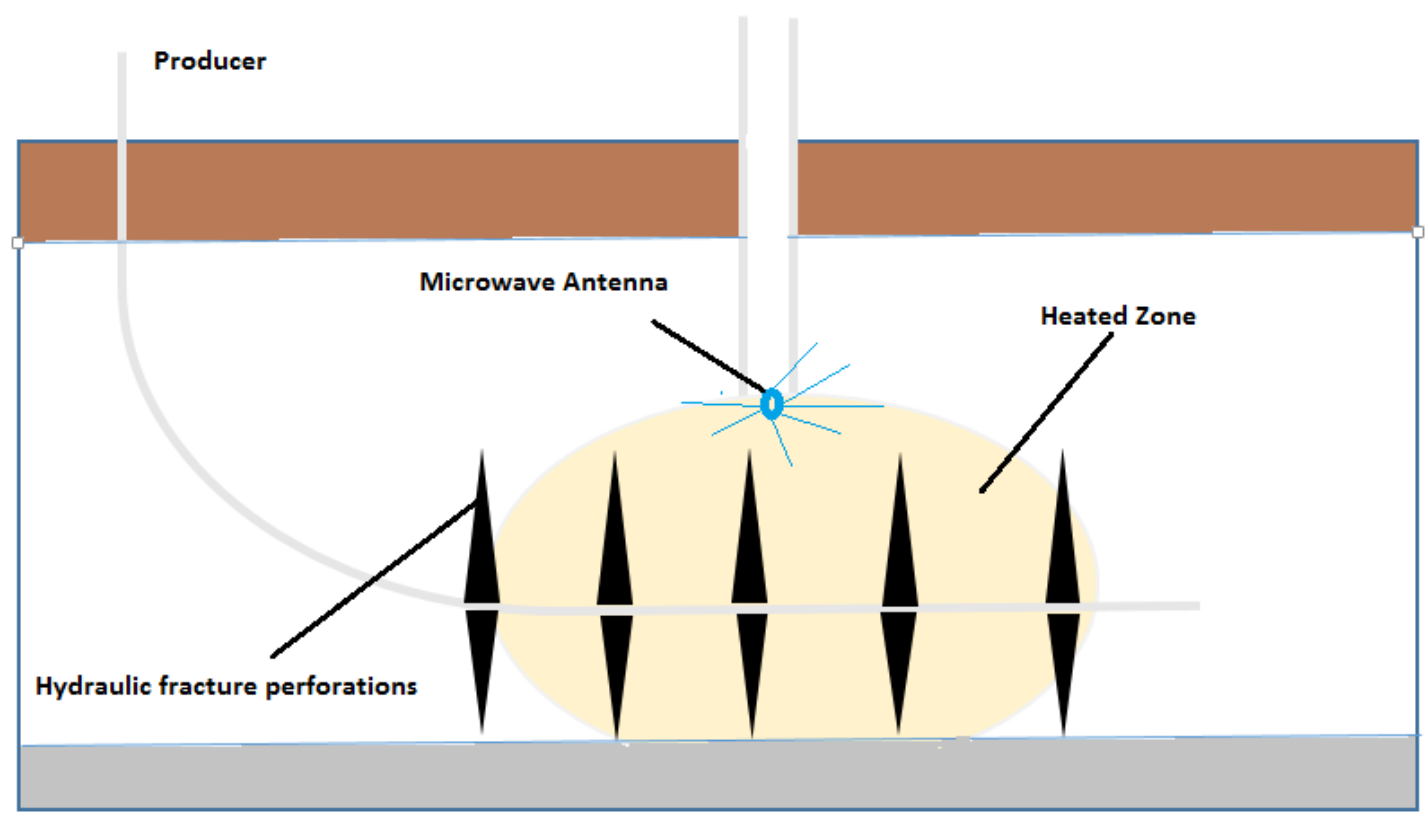

Figure 2: schematics of microwave heating in a shale reservoir 
Table 1: Parameters used in simulation study

\begin{tabular}{|l|l|l|}
\hline Parameters & Value & Reference \\
\hline Microwave frequency & $2.45 \mathrm{GHz}$ & (Abdulrahman and Meribout, 2014) \\
\hline Dielectric Constant & 3 & (Josh et al., 2012) \\
\hline Loss Factor & 0.2 & (Al-Harahsheh et al., 2009) \\
\hline Heat capacity of shale (J/K/kg) & 1000 & (Wang et al., 2017) \\
\hline Thermal Conductivity (W/M/K) & 4 & (Wang et al., 2017) \\
\hline Initial reservoir Pressure (psia) & 1508.39 & (Formatting Citation \\
\hline Initial reservoir temperature( $\left.{ }^{\circ} \mathrm{R}\right)$ & 579.6 & (Guo et al., 2015) \\
\hline Bottom hole pressure (psia) & 500 & (Guo et al., 2015) \\
\hline Reservoir depth & $5463 \mathrm{ft}$ & (Guo et al., 2015) \\
\hline Pressure gradient & $0.54 \mathrm{psi} / \mathrm{ft}$ & (Guo et al., 2015) \\
\hline Matrix initial permeability & $0.04 \mathrm{mD}$ & (Guo et al., 2015) \\
\hline Fracture initial permeability & $10 \mathrm{mD}$ & (Guo et al., 2015) \\
\hline Matrix porosity & 0.05 & (Guo et al., 2015) \\
\hline Fracture porosity & 0.001 & (Guo et al., 2015) \\
\hline Molecular Weight (CH4) & $0.016 \mathrm{lb} / \mathrm{lb} \mathrm{mole}$ & \\
\hline Standard gas volume & $0.7910 \mathrm{scf} / \mathrm{mol}$ & (Guo et al., 2015) \\
\hline Langmuir pressure & $300 \mathrm{psia}$ & (Guo et al., 2015) \\
\hline Langmuir volume & $2.83 \times 10^{-3} \mathrm{~m}^{3} / \mathrm{kg}$ & (Guo et al., 2015) \\
\hline Shale rock density & $2550 \mathrm{~kg} / \mathrm{m3}$ & (Guo et al., 2015) \\
\hline Initial gas viscosity & $1.02 \times 10^{-5}$ Pa.s & (Guo et al., 2015) \\
\hline Wellbore radius & $0.328 \mathrm{ft}$ & (Guo et al., 2015) \\
\hline Fracture spacing & $0.656 \mathrm{ft}$ & (Guo et al., 2015) \\
\hline
\end{tabular}

To solve for the gas production in shale gas reservoir associated with microwave heating, a couple electromagnetic - thermal model has been developed for shale gas reservoir in MATLAB. The process of coupling all of the equations are described using figure 3 . Segregated solution approach have been adopted to couple all the system of non- linear partial differential equations while the Newton's method have been used to solve the non-linearity of the differential equations. 


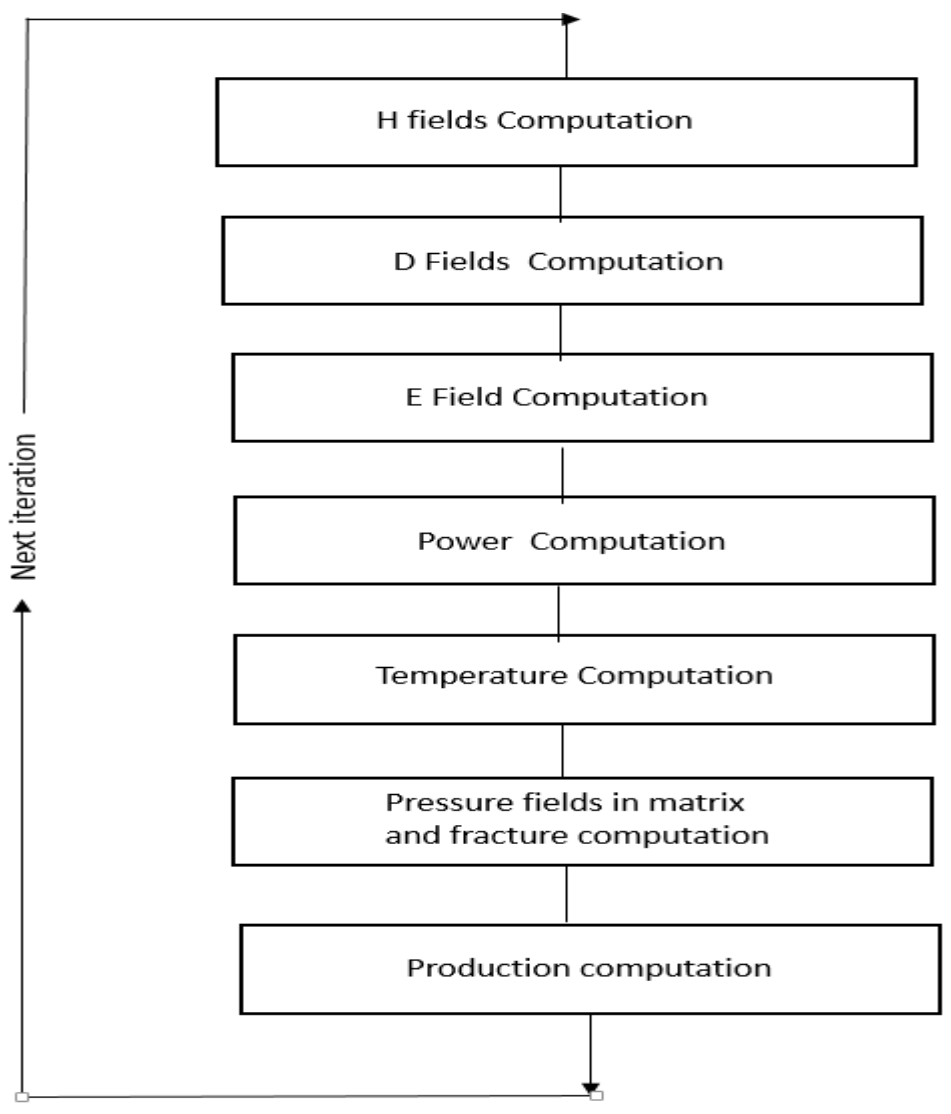

Figure 1: Combined electromagnetic, thermal and production algorithm for a shale gas reservoir

\subsection{Model Validation}

Guo et al. (2015) noted that there are no real field data that is similar to the theoretical case developed above for the governing mathematical equations for flow of gas in shale gas reservoir, it is expected that the analytical results can be compared with the numerical simulation to verify the righteousness of the results. Thus by simplifying equation 11 into a one dimensional, linear , horizontal and steady state flow condition (See Eq 45), the results can be compared with the analytical solution derived by Wu et al.(1998) for a 1D steady -state gas transport.

$$
\frac{\partial}{\partial x}\left(\frac{k_{\infty} \beta(P+b)}{\mu} \frac{\partial P}{\partial x}\right)=0
$$

The boundary conditions given for the solution of the steady-state gas transport are: A constant mass injection rate $q_{m}$ per unit cross-sectional area is imposed at the inlet ( $\left.x=0\right)$ and Gas 
pressure is kept constant at the outlet $(x=L)$. The analytical solution is given by Wu et al. (1998) as

$$
p(x)=-b+\sqrt{b^{2}+\left(p(L)^{2}+2 b[p(L)]+\frac{2 q_{m} u_{g}(L-x)}{k_{\infty} \beta}\right)}
$$

The results from numerical simulation of equation 45 (See figure 4 ) shows a clear and exact match to the analytical solution developed by Wu et al.(1998) implying that our model is cable of representing the flow conditions in a shale gas reservoir.

Reda (1987) carried out experimental study of the welded tuff at Yucca Mountain with the following properties used in the verification of the analytical model given below:

$b$ (Klinkenberg factor) $=7.6 \times 10^{5} \mathrm{~Pa}, p(L)$ is the gas pressure at the outlet $=1.0 \times 10^{-5} \mathrm{~Pa} . \mathrm{s}, L$ is the length from the inlet to the outlet $=10 \mathrm{~m}, x$ is the task location along the gas transport path , $k_{\infty}$ is the intrinsic permeability $=5.0 \times 10^{-19} \mathrm{~m}^{2}, \beta$ is the compressibility factor $=$ $1.8 \times 10^{-5} \mathrm{~Pa}^{-1} \mathrm{~m}^{-1}, q_{m}$ is the air injection rate $=1.0 \times 10^{-6} \mathrm{~kg} / \mathrm{s}, u_{g}$ is the dynamic viscosity= $1.84 \times 10^{-5}$ Pa.s 


\section{Model Validation}

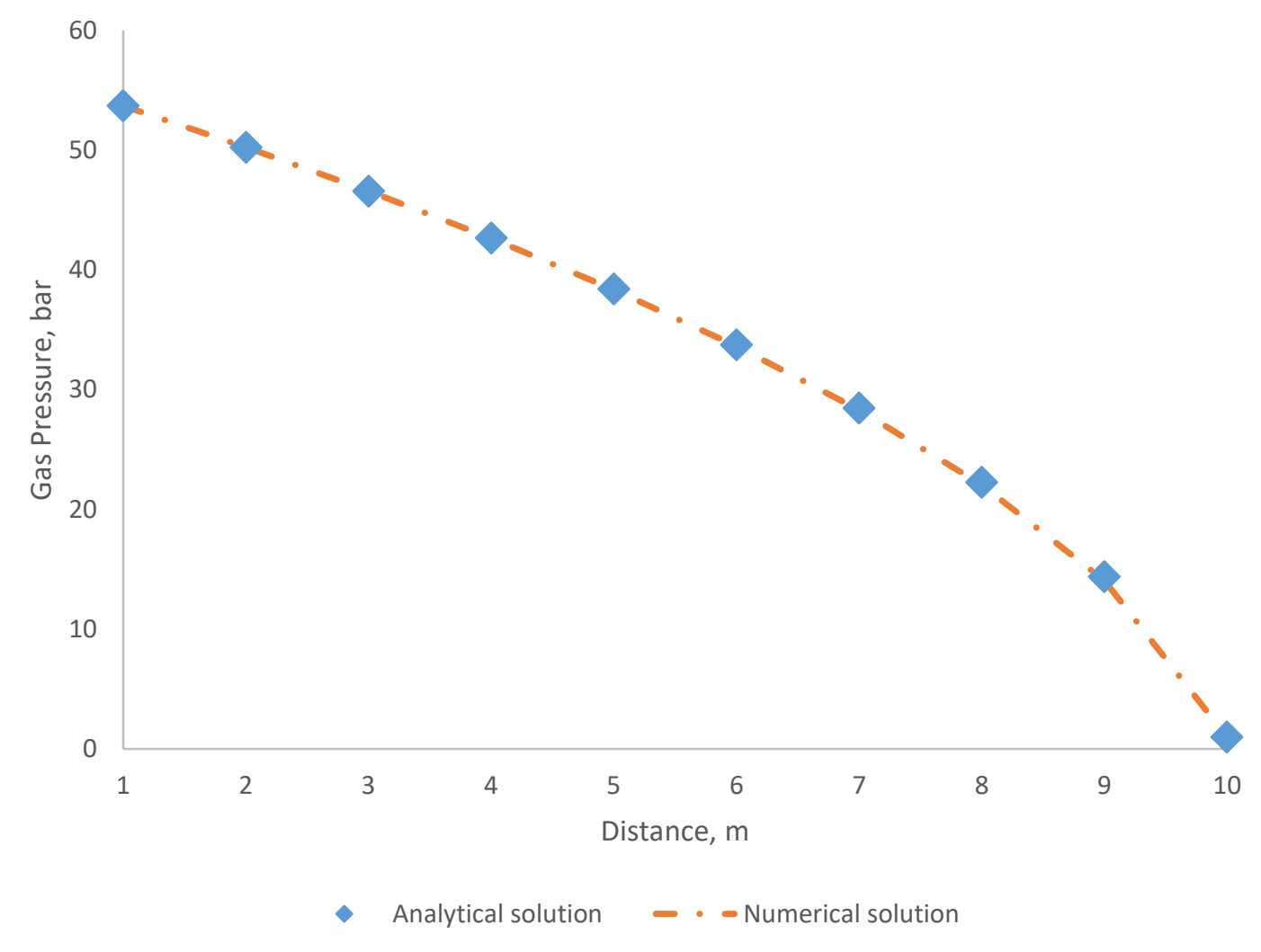

Figure 2: Comparison of numerical and analytical solution for steady state gas flow in a finite linear system.

\section{Results and Discussion}

\subsection{Effect of microwave heating on gas production}

The effect of microwave heating on production rate and cumulative production can be observed in figure 5-6. From figure 5, production rate increases considerably where microwave heating is applied compared with where there is no microwave heating. This is because the application of microwave heating ensures an increase in temperature of the formation which consequently increases desorption of the adsorbed gas. The contribution from the adsorbed gas therefore enhances the production rate from the reservoir. After 360 days, microwave heating contributes to overall cumulative production by $25 \%$ compared with where there is no microwave heating. 


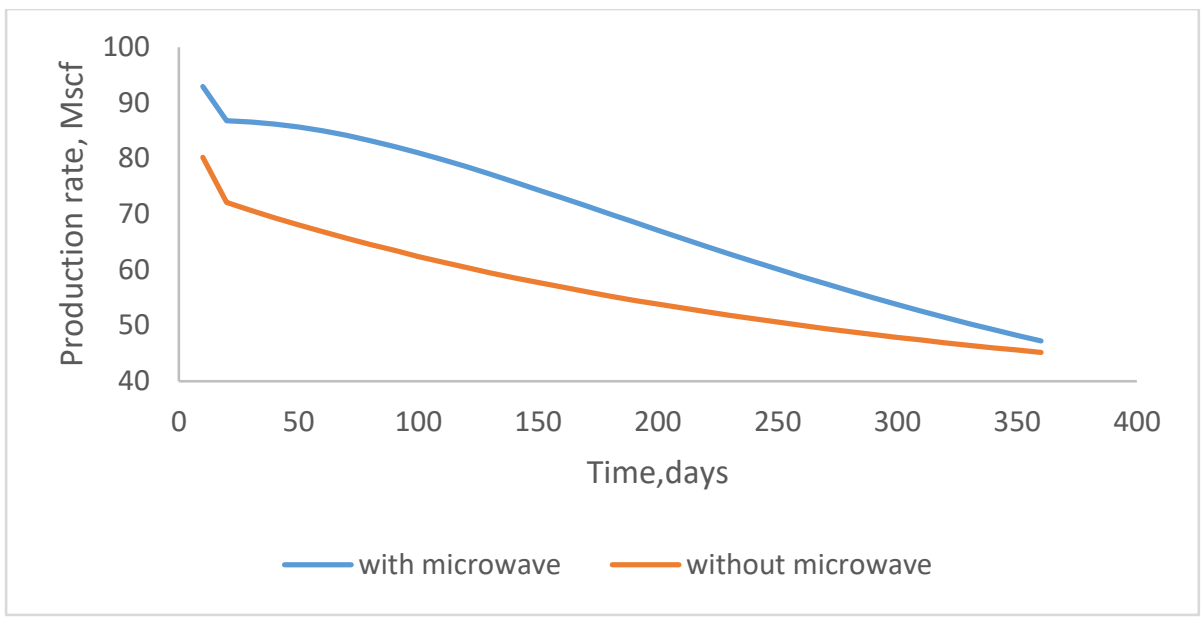

Figure 3: Production rate with and without microwave heating

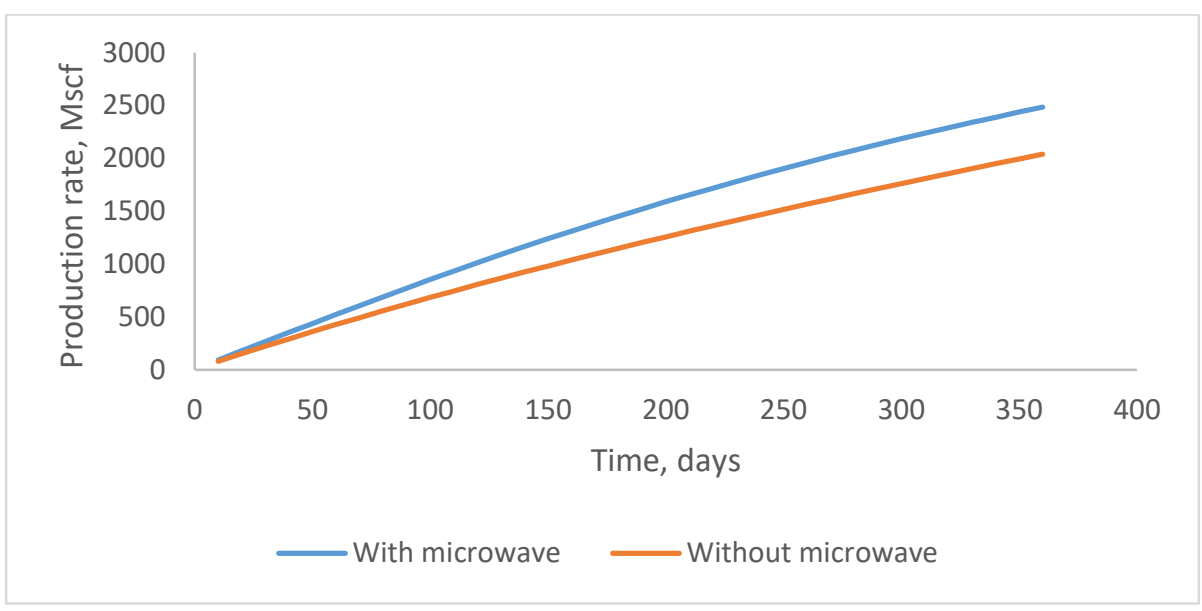

Figure 4 : Cumulative production with and without microwave heating

\subsection{Temperature distribution}

Figure 7 shows temperature distributions in the reservoir following microwave heating at different heating time periods ranging from 90 days, 180 days and 360 days. Temperature is highest at the centre where the microwave radiation is emitted and gradually decreases at surrounding nodes. As the heating time increases and reaches 360 days, it can be observed that, the central node where the microwave pulse is excited has the highest temperature distribution. Also, the average temperature throughout the reservoir rises as the microwave heating continues around the central node where the waveguide is located and remains relatively the same as the initial temperature of $579.6^{\circ} \mathrm{R}$, further away from the waveguide. 


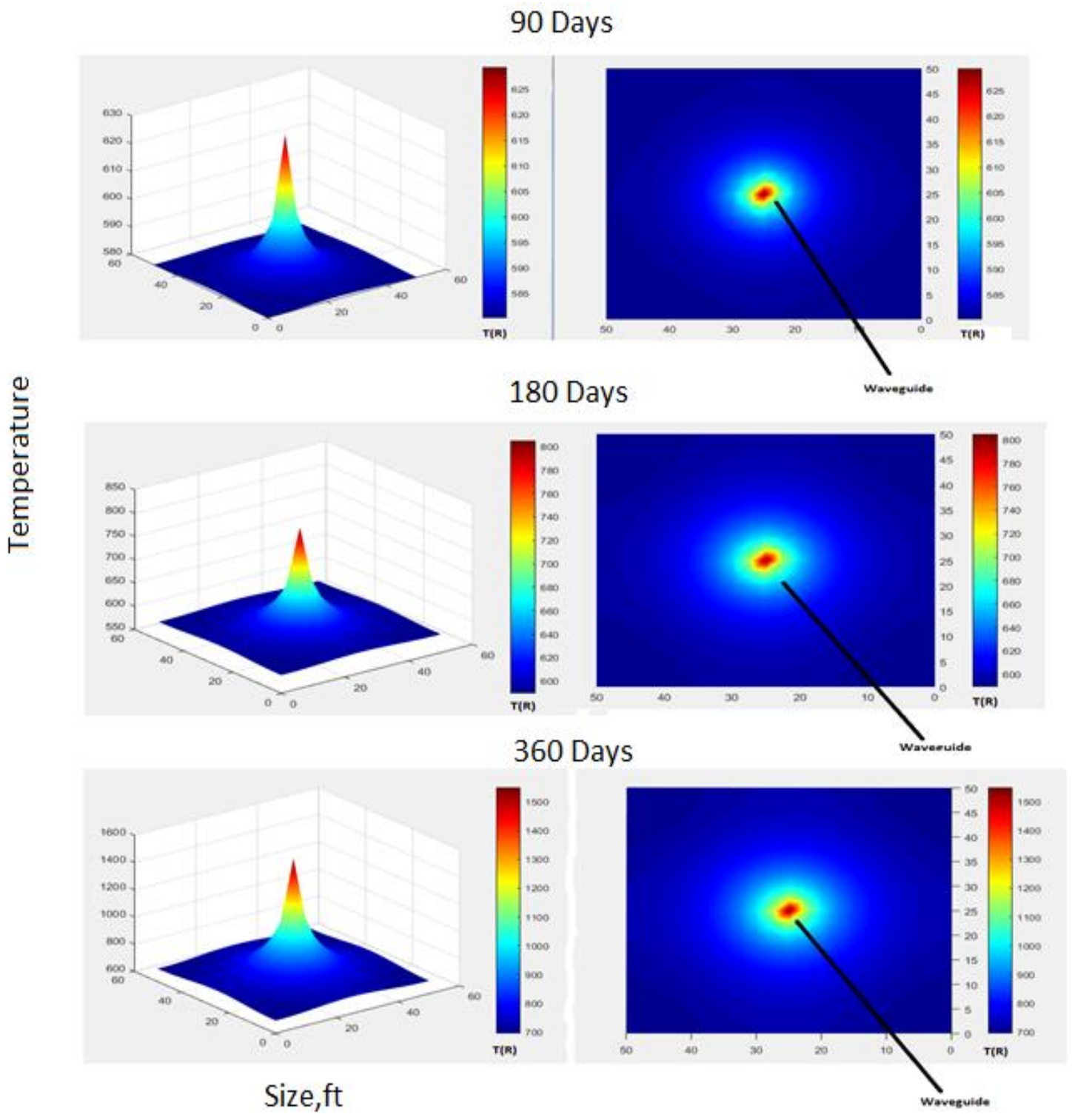

Figure 7: Temperature distribution after 90,180 and 360 days of microwave heating

\subsection{Effect of microwave frequency}

Frequency ranges that are normally suggested for industrial microwave processing include $915 \mathrm{MHz}$, $2450 \mathrm{MHz}$ and $5800 \mathrm{MHz}$ (li et al 2017, Peng et al 2011). Different frequency range used in microwave heating can affect temperature differential within the material or as in this case the reservoir formation. The choice of different frequency also have significant effect on production in shale gas reservoir. In order to demonstrate the effect of microwave heating, three frequency ranges 
of $915 \mathrm{MHz}, 2450 \mathrm{MHz}$ and $5800 \mathrm{MHz}$ have been chosen and this resulted in different temperature profiles as shown in figures 8-10. Critical observation of figures 8-10 shows that higher microwave frequency results in relatively higher temperature profile. However, the increase in temperature for higher microwave frequency is only observed at the surface of the material whereas for lower frequencies, temperature rises more than the higher frequencies at the inner section of the sample. This is because, the penetration depth for high microwave frequency is much lower compared with the penetration depth of lower microwave frequency (Peng et al 2011). The penetration depth is however strongly dependent on the dielectric properties of the material which is also heavily dependent on microwave frequency and temperature. Thus, there would be a poor heating efficiency at the higher frequency range of $5800 \mathrm{MHz}$ and $2450 \mathrm{MHz}$ compared with $915 \mathrm{MHz}$ since energy would be easily lost to the surroundings. The greater energy efficiency at the lower frequency range of $915 \mathrm{MHz}$ would lead to an increase in production and ultimately higher cumulative production compared with a high frequency of $2450 \mathrm{MHz}$ as seen in figures 1112.Production Rate is highest when frequency is lowest at $915 \mathrm{MHz}$ and lowest at the high frequency of $5800 \mathrm{MHz}$ as seen from figure 11. In figure 12 , overall cumulative production is highest at frequency of $915 \mathrm{MHz}$ compared with frequency of $2450 \mathrm{MHz}$ and $5800 \mathrm{MHz}$.

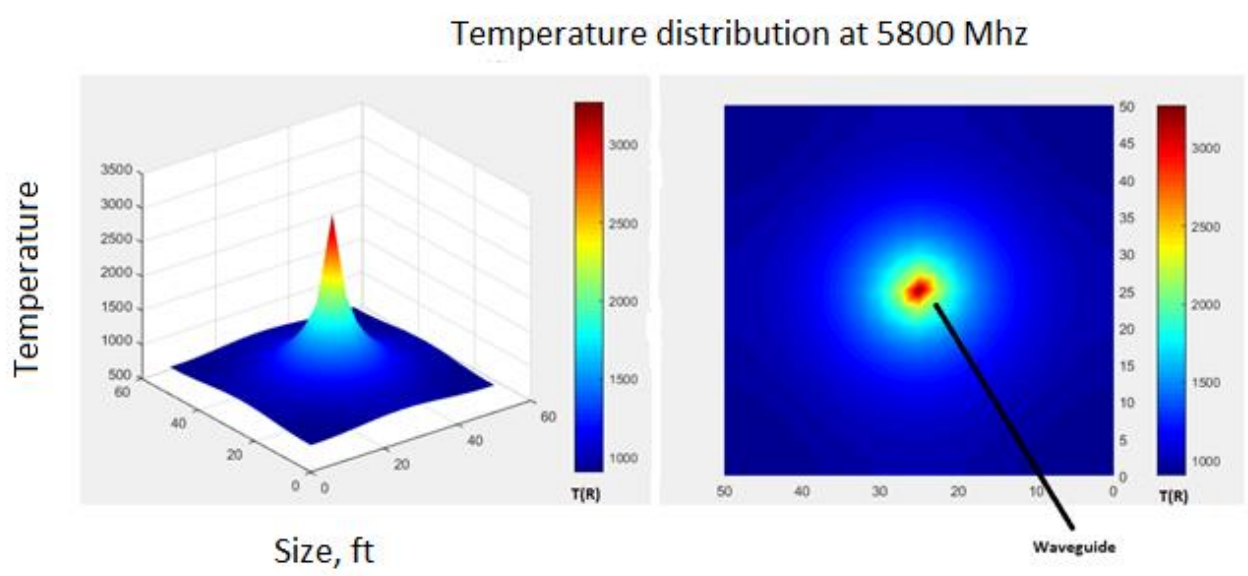

Figure 8: Temperature distribution at $5800 \mathrm{MHz}$ at time 360 days 
Temperature distribution at 2450

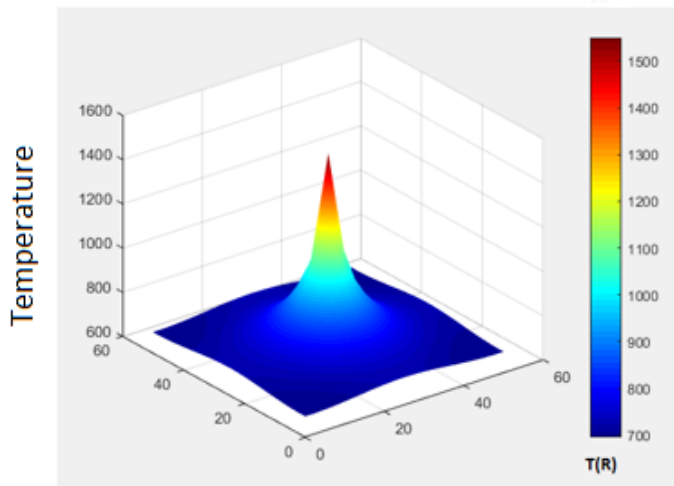

Size, ft

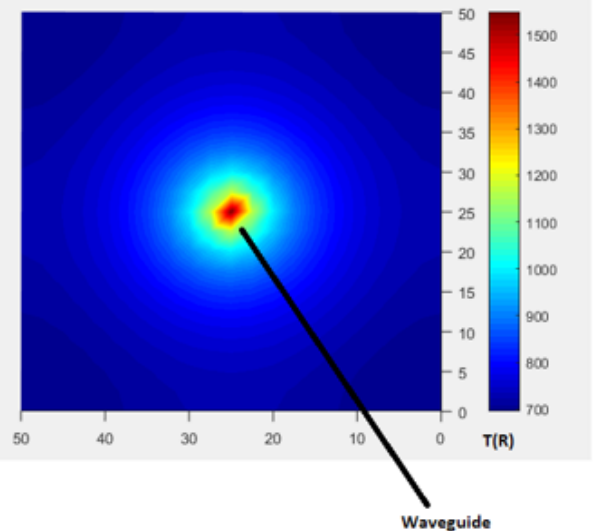

Figure 9: Temperature distribution at $2450 \mathrm{MHz}$ at time 360 days

Temperature distribution at $915 \mathrm{MHz}$

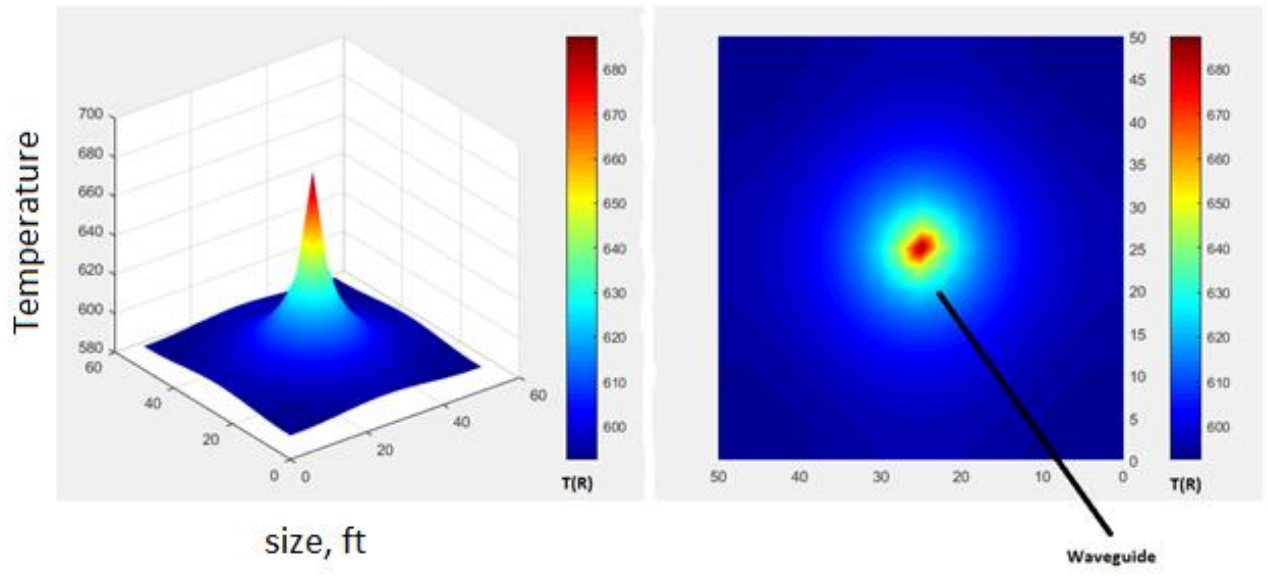

Figure 10: Temperature distribution at $915 \mathrm{MHz}$ at time 360 days 


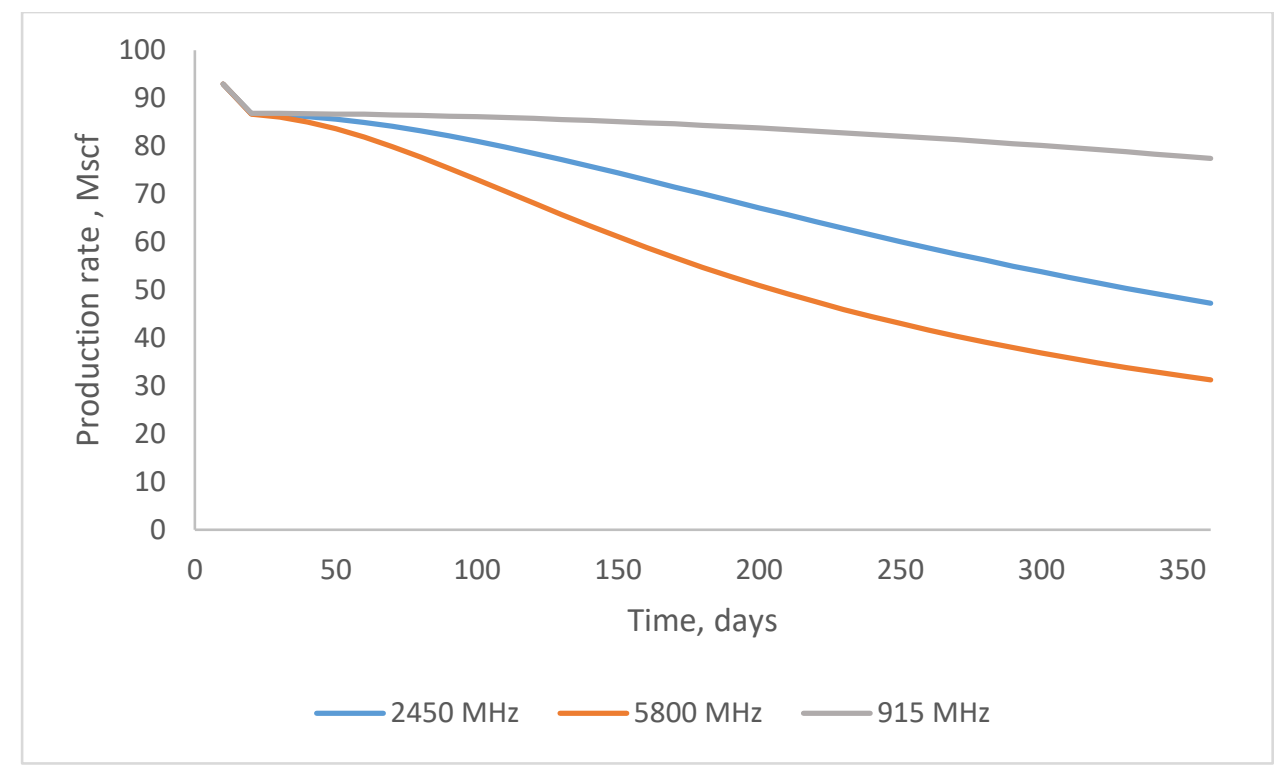

Figure 11: Production rate at frequency of 915,2450 and $5800 \mathrm{MHz}$

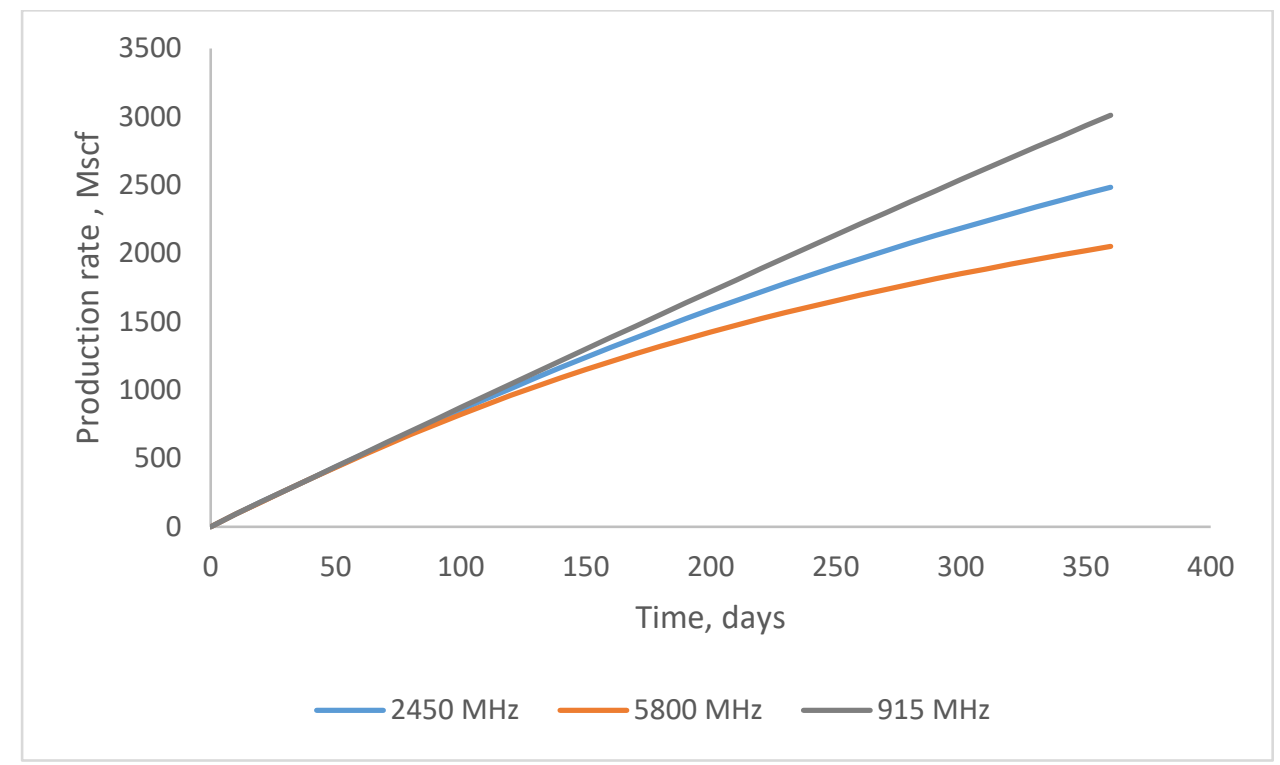

Figure 12: Cumulative production at frequency of 915,2450 and $5800 \mathrm{MHz}$

\subsection{Effect of microwave heating on free gas content}

According to Mariotte's law, free gas content can be predicted by (Liu et al 2012, li et al 2017) 


$$
V_{g}=\frac{\phi P T_{s}}{P_{s} T \rho_{s}}
$$

Where $V_{g}$ is the free gas content, $P$ is the gas pressure, $T$ is the reservoir temperature, $\rho_{s}$ is the density of shale, $T_{s}$ and $P_{s}$ represents the temperature and pressure at standard conditions. From figures 13-14, we can observe the evolution of the gas content with and without microwave heating. Reliance on normal pressure depletion mechanism without any heating shows very small changes in the gas content. We can observe that, gas content around the location of the wellbore is lower than that further away from the wellbore. However, with microwave heating after a period of 360 days, there is a considerable drop in the gas content around the wellbore and waveguide. Also, the gas drainage is much higher further away from the wellbore for microwave heating compared with the case of no microwave heating. This is because the areas affected by the microwave heating results in desorption of the gas. Therefore as the temperature rises, there is a resulting decrease in the gas content.

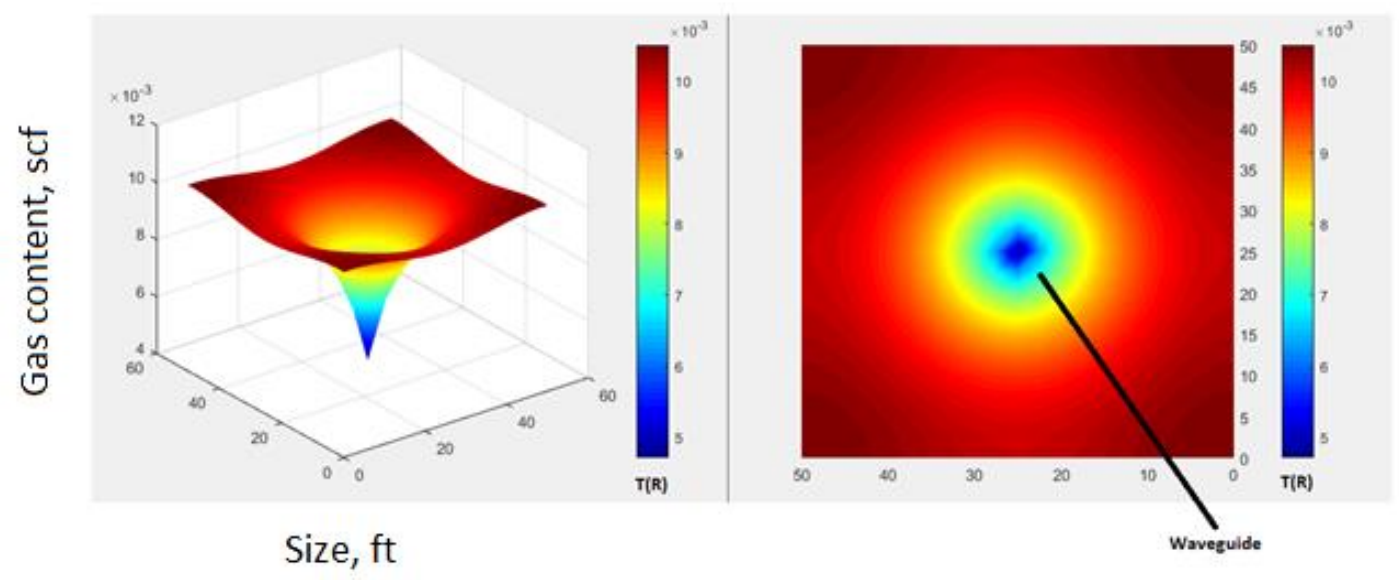

Figure 13: Free gas content evolution with microwave heating at 360 days 


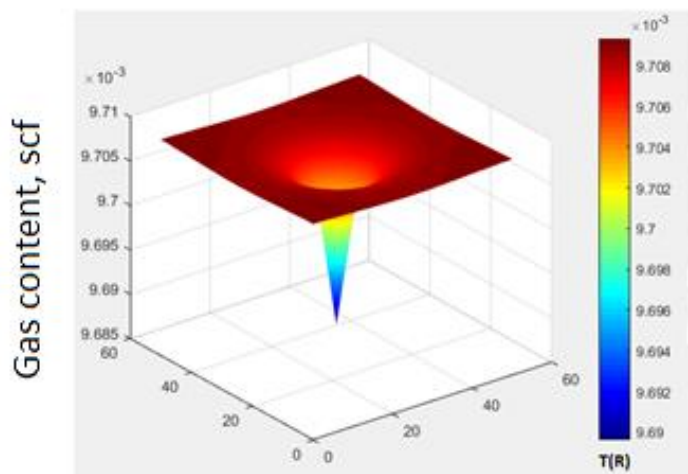

Size, $\mathrm{ft}$

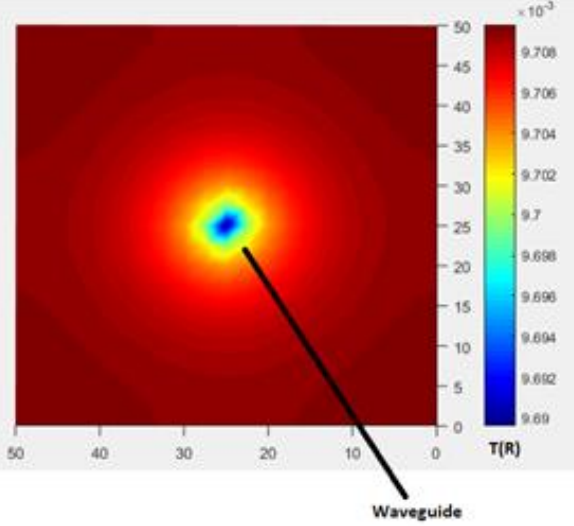

Figure 14: Free gas content without microwave heating at 360 days

\section{Conclusion:}

In this paper, a fully coupled electromagnetic-thermal reservoir model have been developed to investigate the impact of thermal stimulation on shale gas recovery. Several factors such as microwave frequency, have been investigated to assess their impact on the effectiveness of thermal stimulation. In this proposed model, Non-Darcy flow effect is considered in the mathematical formulation of shale gas system. Microwave heating has been particular chosen as the heat source. In order to couple the heat source from the microwave to the shale system, Maxwell equations which describes electromagnetism have been solved using a finite difference time domain method (FDTD). This methodology involved solving for the electric field using a leapfrog approach. A transverse electric (TE) mode has been chosen as the propagating mode. The results show that thermal stimulation using microwave heating has the potential to increase cumulative gas production by as much as $25 \%$ compared with normal recovery method without any thermal stimulation. The frequency range of $915 \mathrm{MHz}$ was also found to be optimal in increasing gas recovery based on this study. By considering the Non-Darcy flow effect in this coupled electromagnetic model, shale gas recovery can be predicted especially where adsorbed gas is targeted and provides useful basis for further research into microwave heating in shale gas. 


\section{Nomenclature}

Specific surface area

M Mass accumulation

Mw Molecular weight

Heat transfer coefficient

$\rho$

Density

$P_{o}$

Surface power

$u$

Viscosity

Maximum distance

$q_{a d s}$

Gas adsorption

$Q$

Absorbed power

$\phi$

Porosity

$\alpha$

Attenuation factor

$k_{m}$

Matrix apparent permeability

Z

Gas deviation factor

$k_{f} \quad$ Fracture apparent permeability

$p \quad$ Pressure

H Magnetic field,

$V_{L} \quad$ Langmuir volume

D Electric flux density

$T_{g}$

Gas transfer term

B

Magnetic flux density,

T Temperature

J

Electric current density

$\Delta H$

Adsorption enthalpy

$\varepsilon$

Permittivity

$R$

Universal gas constant

$\mu$

Magnetic Permeability.

$P_{L}$

Langmuir pressure

$\varepsilon$

Dielectric constant

$L_{x}, L_{y}, L_{z} \quad$ Fracture spacing in $\mathrm{x}, \mathrm{y}$ and $\mathrm{z}$

$\varepsilon$

Dielectric loss factor

$\sigma$

Crossflow coefficient

$\mathrm{T}(\mathrm{R}) \quad$ Temperature in Rankine

$q_{p}$

Gas production sink term

TEM Transverse electromagnetic

$c_{p}$

Specific heat capacity

TE Transverse Electric

TM Transverse Magnetic

$k_{T} \quad$ Thermal conductivity 


\section{Subscripts}

$\begin{array}{ll}g & \text { Gas } \\ f & \text { Fracture } \\ m & \text { Matrix } \\ s & \text { Shale } \\ r & \text { Relative } \\ f l & \text { Fluid } \\ p a & \text { Particle }\end{array}$

\begin{tabular}{|l|l|}
\hline Equation & Reference \\
\hline $\begin{array}{l}\text { Equation 1-4, 6-10, } \\
\text { 13-14 }\end{array}$ & Guo et al.,2015 \\
\hline Equation 15-20 & Guo et al.,2015 \\
\hline
\end{tabular}




\section{References}

Abdulrahman, M.M., Meribout, M., 2014. Antenna array design for enhanced oil recovery under oil reservoir constraints with experimental validation. Energy 66, 868-880. https://doi.org/10.1016/j.energy.2014.01.002

Akram, G., Jasmy, Y., 2012. Simulation of the finite difference time domain in two dimension 6, 717721.

Al-Harahsheh, M., Kingman, S., Saeid, A., Robinson, J., Dimitrakis, G., Alnawafleh, H., 2009. Dielectric properties of Jordanian oil shales. Fuel Process. Technol. 90, 1259-1264.

https://doi.org/10.1016/j.fuproc.2009.06.012

Busch, A., Amann-Hildenbrand, A., 2013. Predicting capillarity of mudrocks. Mar. Pet. Geol. 45, 208223. https://doi.org/10.1016/j.marpetgeo.2013.05.005

Campañone, L.A., Zaritzky, N.E., 2005. Mathematical analysis of microwave heating process. J. Food Eng. 69, 359-368. https://doi.org/10.1016/j.jfoodeng.2004.08.027

Chaiyo, K., Rattanadecho, P., 2013. Numerical analysis of heat-mass transport and pressure buildup of unsaturated porous medium in a rectangular waveguide subjected to a combined microwave and vacuum system. Int. J. Heat Mass Transf. 65, 826-844. https://doi.org/10.1016/j.ijheatmasstransfer.2013.06.066

Chapiro, G., Bruining, J., 2015. Combustion enhance recovery of shale gas. J. Pet. Sci. Eng. 127, 179189. https://doi.org/10.1016/j.petrol.2015.01.036

Charoensuppanimit, P., Mohammad, S.A., Robinson, R.L., Gasem, K.A.M., 2015. Modeling the temperature dependence of supercritical gas adsorption on activated carbons, coals and shales. Int. J. Coal Geol. 138, 113-126. https://doi.org/10.1016/j.coal.2014.12.008

Chekhonin, E., Parshin, A., Pissarenko, D., Popov, Y., Romushkevich, R., Safonov, S., Spasennykh, M., Chertenkov, M. V., Stenin, V.P., 2012. When rocks get hot: thermal properties of reservoir rocks. Oilf. Rev. Autumn 3, 20-37.

Chen, S., Jin, L., Chen, X., 2011. The effect and prediction of temperature on adsorption capability of coal/CH 4. Procedia Eng. 26, 126-131. https://doi.org/10.1016/j.proeng.2011.11.2149

Clarkson, C.R., 2003. Application of a new multicomponent as adsorption model to coal gas adsorption systems. SPE J. 8, 236-251. https://doi.org/10.2118/78146-PA 
Denny, D., 2007. Cleaning up water blocking in gas reservoirs by microwave Heating 0-2.

Farag, S., Sobhy, A., Akyel, C., Doucet, J., Chaouki, J., 2012. Temperature profile prediction within selected materials heated by microwaves at $2.45 \mathrm{GHz}$. Appl. Therm. Eng. 36, 360-369. https://doi.org/10.1016/j.applthermaleng.2011.10.049

Fianu, John, Gholinezhad, J., Hassan, M., 2018. Comparison of temperature dependent Gas adsorption models and their application to shale gas reservoirs. Energy \& Fuels acs.energyfuels.8b00017. https://doi.org/10.1021/acs.energyfuels.8b00017

Gasparik, M., Gensterblum, Y., Ghanizadeh, A., Weniger, P., Krooss, B.M., 2015. High-Pressure/Hightemperature methane-sorption measurements on carbonaceous shales by the manometric method: experimental and data-evaluation considerations for improved accuracy. SPE J. 20, 790-809. https://doi.org/10.2118/174543-PA

Guo, C., Wei, M., Liu, H., 2015a. Modeling of gas production from shale reservoirs considering multiple transport mechanisms. PLoS One 10, 1-24. https://doi.org/10.1371/journal.pone.0143649

Guo, S., 2013. Experimental study on isothermal adsorption of methane gas on three shale samples from Upper Paleozoic strata of the Ordos Basin. J. Pet. Sci. Eng. 110, 132-138. https://doi.org/10.1016/j.petrol.2013.08.048

Hiebert, A.D., Vermeulen, F.E., Chute, F.S., Capjack, C.E., 1986. Numerical simulation results for the electrical heating of athabasca Oil-Sand Formations. SPE Reserv. Eng. 1, 76-84. https://doi.org/10.2118/13013-PA

Hossan, M.R., Dutta, P., 2011. Analytical solution for temperature distribution in microwave heating of rectangular objects, in: ASME 2011 International Mechanical Engineering Congress and Exposition. pp. 623-628.

$\mathrm{Hu}, \mathrm{H} ., 2014$. Methane adsorption comparison of different thermal maturity kerogens in shale gas system. Chinese J. Geochemistry 33, 425-430. https://doi.org/10.1007/s11631-014-0708-9

Jamaluddin, A.K.M., Bennion, D.B., Thomas, F.B., Ma, T.Y., 2000. Application of heat treatment to enhance permeability in tight gas reservoirs. J. Can. Pet. Technol. 39, 19-24.

Ji, W., Song, Y., Jiang, Z., Wang, X., Bai, Y., Xing, J., 2014. Geological controls and estimation algorithms of lacustrine shale gas adsorption capacity: A case study of the Triassic strata in the southeastern Ordos Basin, China. Int. J. Coal Geol. 134-135, 61-73. 
https://doi.org/10.1016/j.coal.2014.09.005

Josh, M., Esteban, L., Delle Piane, C., Sarout, J., Dewhurst, D.N., Clennell, M.B., 2012. Laboratory characterisation of shale properties. J. Pet. Sci. Eng. 88-89, 107-124.

https://doi.org/10.1016/j.petrol.2012.01.023

Klayborworn, S., Pakdee, W., Rattanadecho, P., Vongpradubchai, S., 2013. Effects of material properties on heating processes in two-layered porous media subjected to microwave energy. Int. J. Heat Mass Transf. 61, 397-408.

https://doi.org/10.1016/j.ijheatmasstransfer.2013.02.020

Lee, A., Gonzalez, M., Eakin, B., 1966. The viscosity of natural gases. J. Pet. Technol. 18, 997-1000. https://doi.org/http://dx.doi.org/10.2118/1340-PA

Li, H., Lin, B., Yang, W., Hong, Y., Wang, Z., 2017. A fully coupled electromagnetic-thermalmechanical model for coalbed methane extraction with microwave heating. J. Nat. Gas Sci. Eng. 46, 830-844. https://doi.org/10.1016/j.jngse.2017.08.031

Liu, J., Wang, J., Leung, C., Gao, F., 2018. A fully coupled numerical model for microwave heating enhanced shale gas recovery. Energies 11, 12-14. https://doi.org/10.3390/en11061608

Lu, X.-C., Li, F.-C., Watson, T.A., 1995. Adsorption studies of natural gas storage in devonian shales.

Mutyala, S., Fairbridge, C., Paré, J.R.J., Bélanger, J.M.R., Ng, S., Hawkins, R., 2010. Microwave applications to oil sands and petroleum: A review. Fuel Process. Technol. 91, 127-135. https://doi.org/10.1016/j.fuproc.2009.09.009

Pincombe, A.H., Smyth, N.F., 1991. Microwave heating of materials with low conductivity. Proc. R. Soc. Lond. A 433, 479-498.

Rathi, V., Shrivastava, P.K., Pokhariya, H.S., 2012. 1-D Implementation of Maxwell' s Equations in MATLAB to Study the Effect of Absorption Using PML. Int. J. Electron. Syst. 64-69.

Reda, D.C., 1987. Slip-flow experiments in welded tuff, in: coupled processes associated with nuclear waste repositories.

Rexer, T.F.T., Benham, M.J., Aplin, A.C., Thomas, K.M., 2013. Methane adsorption on shale under simulated geological temperature and pressure conditions $\backslash$ TThomas F. T. Rexer, $\uparrow$ Michael J. Benham,‡ Andrew C. Aplin,§ and K. Mark Thomas. Energy \& Fuels 27, 3099-3109.

Sahni, A., Kumar, M., Knapp, R.B., 2000. Electromagnetic heating methods for heavy oil reservoirs. 
SPE/AAPG West. Reg. Meet. 2000 1-10. https://doi.org/10.2118/62550-MS

Salmachi, A., Haghighi, M., 2012. Feasibility study of thermally enhanced gas recovery of coal seam gas reservoirs using geothermal resources. Energy \& Fuels 26, 5048-5059.

https://doi.org/10.1021/ef300598e

Santos, J. E., Savioli, G. B., Carcione, J. M., \& Ba, J. (2019). Effect of capillarity and relative permeability on $\mathrm{Q}$ anisotropy of hydrocarbon source rocks. Geophysical Journal International, 218(2), 1199-1209.

Sanmiguel, J.E., Mallory, D.G., Mehta, S.A., Moore, R.G., 2002. Formation heat treatment process by combustion of gases around the wellbore. J. Can. Pet. Technol. 41, 70-76. https://doi.org/10.2118/02-08-05

Sierra, R., Tripathy, B., Bridges, J.E., Farouq Ali, S.M., 2001. Promising progress in field application of reservoir electrical heating methods. SPE Int. Therm. Oper. Heavy Oil Symp. 1-17. https://doi.org/10.2118/69709-MS

Sullivan, D.M., 2000. Electromagnetic simulation using the FDTD method. IEEE Press Ser. RF Microw. Technol. https://doi.org/10.1109/9780470544518

Sun, J., Wang, W., Yue, Q., 2016. Review on microwave-matter interaction fundamentals and efficient microwave-associated heating strategies. Materials (Basel). 9. https://doi.org/10.3390/ma9040231

Toroğlu, G., Sevgi, L., 2014. Matlab codes for first and second order EM differential equations. IEEE Antennas Propag. Mag. 56.

Torres, F., Jecko, B., 1997. Complete FDTD analysis of microwave heating processes in frequencydependent and temperature-dependent media. IEEE Trans. Microw. Theory Tech. 45, 108-117. https://doi.org/10.1109/22.552039

Wang, H., 2016. A numerical study of thermal-hydraulic-mechanical (THM) simulation with the application of thermal recovery in fractured shale gas reservoirs. SPE Reserv. Eval. Eng. 00000, 0-34. https://doi.org/10.3837/tiis.0000.00.000

Wang, H., Merry, H., Amorer, G., Kong, B., 2015. Enhance hydraulic fractured coalbed methane recovery by thermal stimulation. SPE/CSUR Unconv. Resour. Conf. c. https://doi.org/10.2118/175927-MS

Wang, Y. dou, Wang, X. ying, Xing, Y. fan, Xue, J. kang, Wang, D. sheng, 2017. Three-dimensional 
numerical simulation of enhancing shale gas desorption by electrical heating with horizontal wells. J. Nat. Gas Sci. Eng. 38, 94-106. https://doi.org/10.1016/j.jngse.2016.12.011

Wu, Y.-S., Pruess, K., Persoff, P., 1998. Gas flow in porous media with klinkenberg effects. Transp. Porous Media 32, 117-137. https://doi.org/10.1023/A:1006535211684

Ye, Z., Chen, D., Pan, Z., Zhang, G., Xia, Y., Ding, X., 2016. An improved langmuir model for evaluating methane adsorption capacity in shale under various pressures and temperatures. J. Nat. Gas Sci. Eng. 31, 658-680. https://doi.org/10.1016/j.jngse.2016.03.070

Yee, K., 1966. Numerical solution of initial boundary value problems involving Maxwell's equations in isotropic media. Antennas Propagation, IEEE Trans. https://doi.org/10.1109/TAP.1966.1138693

Yue, L., Wang, H., He, S., Nikolaou, M., 2015. Increasing shale gas recovery through thermal stimulation : analysis and an experimental study.

Zhao, X., Huang, K., Yan, L., 2011. Review of numerical simulation of microwave heating process. INTECH Open Access Publ. 27-28. https://doi.org/10.5772/13387

Zhou, L., Puri, V.M., Anantheswaran, R.C., Yeh, G., 1995. Finite element modeling of heat and mass transfer in food materials during microwave heating - Model development and validation. J. Food Eng. 25, 509-529. https://doi.org/10.1016/0260-8774(94)00032-5 